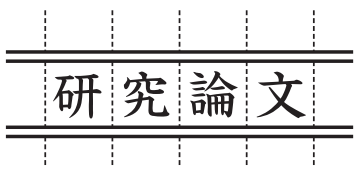

\title{
Formation of Hydroxyapatite/Titania Composite Film with Two Aerosol Beams
}

\author{
Masahiro TSUKAMOTO*, Hitoshi NAKANO** and Nobuyuki ABE*
}

(Received Jun 7, 2010)

\begin{abstract}
A hydroxyapatite/titania composite $\left(\mathrm{HAp} / \mathrm{TiO}_{2}\right)$ film was developed for application in air purification and as an antibacterial, antifouling film. This $\mathrm{HAp} / \mathrm{TiO}_{2}$ film has the ability for adsorbing and decomposing organic matter. To obtain the $\mathrm{HAp} / \mathrm{TiO}_{2}$ film, we used two kinds of aerosol beams. They were composed of $\mathrm{TiO}_{2}$ and $\mathrm{HAp}$ particles accelerated by flow of helium gas, respectively. First layer, $\mathrm{TiO}_{2}$ film, was formed on a glass plate with a $\mathrm{TiO}_{2}$ aerosol beam. Second layer, $\mathrm{HAp}$ film, was created on the first layer, $\mathrm{TiO}_{2}$ film. Neither the substrate nor $\mathrm{HAp}$ and $\mathrm{TiO}_{2}$ particles were heated during deposition. Acetaldehyde concentration reduced by the $\mathrm{HAp} / \mathrm{TiO}_{2}$ film was measured to evaluate the film's ability for adsorbing and decomposing organic matter.
\end{abstract}

Key Words: Hydroxyapatite, Titania, Coating Technology, Film Formation, Aerosol Beam, Composite Fim, Photocatalyst

\section{Introduction}

Anatase phase titanium dioxide $\left(\mathrm{TiO}_{2}\right)$ is widely used in environmental cleaning because of its photocatalytic properties when it is irradiated with ultraviolet (UV) light (wavelength: $\lambda<390 \mathrm{~nm}$ ), enabling decomposition of organic matter such as bacteria, mold and odors. ${ }^{1,2)}$ Drawback of $\mathrm{TiO}_{2}$ is that the photocatalytic properties of $\mathrm{TiO}_{2}$ are not displayed when UV light is absent, such as at night. Therefore, additional function to $\mathrm{TiO}_{2}$, enabling adsorption of organic matter at night, is required. Hydroxyapatite (HAp: $\mathrm{Ca}_{10}\left(\mathrm{PO}_{4}\right)_{6}(\mathrm{OH})_{2}$ ) actively adsorbs organic matter $^{3)}$ without using UV light. However, HAp is not able to decompose it. So its surface becomes saturated with organic matter over time.

A film composed of $\mathrm{TiO}_{2}$ and $\mathrm{HAp}, \mathrm{HAp} / \mathrm{TiO}_{2}$ film, overcomes the respective drawbacks of $\mathrm{TiO}_{2}$ and HAp by both adsorbing and decomposing organic matter, making it highly suitable for environmental cleaning. In previous study, we developed the hybrid aerosol beam (HAB) deposition method for fabricating one layered $\mathrm{HAp} / \mathrm{TiO}_{2}$ film on the substrate. ${ }^{4)} \mathrm{TiO}_{2}$ and $\mathrm{HAp}$ particles were simultaneously ejected from one nozzle in the HAB method. This method is based on coating technology with an aerosol beam. ${ }^{5-8)}$ An aerosol beam is composed of submicronsize particles accelerated by gas flow to velocities of $200-650 \mathrm{~m} / \mathrm{s}$. When a substrate is irradiated with an aerosol beam, the particles collide with the substrate and form a film. During impact, it is probable that some of the kinetic energy of particles is converted into thermal energy that promotes bonding between the particles and the substrate. However, the actual bonding mechanism has not yet been elucidated. In aerosol beam coating, neither the particles nor the substrate are heated during deposition, which is advantageous compared with other coating methods that require high temperatures (e.g., thermal spraying and pulsed laser deposition). Therefore, the particles retain their crystal structure during aerosol beam irradiation.

In this study, we proposed that the coating technology using two kinds of aerosol beams, $\mathrm{TiO}_{2}$ and $\mathrm{HAp}$ aerosol beams, was applied to creation of two layered $\mathrm{HAp} / \mathrm{TiO}_{2}$ film, which had two functions of adsorbing and decomposing organic matter. This film was composed of HAp film on $\mathrm{TiO}_{2}$ film. First layer, $\mathrm{TiO}_{2}$ film, was formed on a glass plate with a $\mathrm{TiO}_{2}$ aerosol beam. Second layer, HAp film, was created on the $\mathrm{TiO}_{2}$ film with a HAp aerosol beam. When HAp film formed on $\mathrm{TiO}_{2}$ film is dense, organic matter can not reach the $\mathrm{TiO}_{2}$. Then, organic matter is not decomposed with UV light since the organic matter does not contact the $\mathrm{TiO}_{2}$ film. When the HAp film is not dense, organic matter can reach the $\mathrm{TiO}_{2}$ film through the HAp film. Then, organic matter is decomposed through photocatalytic effect by UV light irradiation. Our previous study indicated that the density of HAp film could be controlled with variation of the beam incidence angles. When the plate was irradiated with the beam at an oblique incidence, a force is generated parallel to the surface of the plate in addition to the direction of the normal vector. ${ }^{6,8)}$ This force acting parallel to the surface may push and remove particle

* Joining and Welding Research Institute, Osaka University (11-1, Mihogaoka, Ibaraki, Osaka, 567-0047, Japan)

* * Kinki University (3-4-1 Kowakae, Higashi-Osaka, Osaka, 577-8502, Japan) 
aggregates with low adhesion that have already been deposited as more particles fly out from the nozzle. At oblique incidence, the HAp film becomes dense since particle aggregates are removed. We investigated the dependence of the beam incident angle on decomposing organic matter. In this experiment, evaluation of the decomposing organic matter with $\mathrm{HAp} / \mathrm{TiO}{ }_{2}$ film and acetaldehyde in the bottle was performed.

\section{Experimental}

Figure 1 shows a schematic diagram of the aerosol beam processing system for fabricating $\mathrm{HAp} / \mathrm{TiO}_{2}$ film. The film fabrication system with an aerosol beam was primarily composed of an aerosol chamber with a processing chamber connected by a Teflon tube, as shown in Fig. 1. Commercial HAp powders (Taihei Chemical Industrial) and $\mathrm{TiO}_{2}$ powders (Junsei Chemical) were used in our experiments. The HAp particle size was in the 0.1 to $0.5 \mu \mathrm{m}$ range, although aggregates with a diameter of approximately 1 to $2 \mu \mathrm{m}$ were formed. The $\mathrm{TiO}_{2}$ particle size was approximately $0.2 \mu \mathrm{m}$. These sizes were confirmed with a scanning electron microscope (SEM). An aerosol was produced by mixing the particles with helium gas using an aerosol vibration system shown in Fig. 1. The processing chamber was pumped down with a mechanical booster pump and a rotary pump to produce a pressure difference between the two chambers. Helium gas flowed from the aerosol chamber (0.1 MPa) to the processing chamber (300 Pa). Gas flow rate was $20 \mathrm{~L} / \mathrm{min}$. The particles were accelerated by the flow of helium gas and carried to the processing chamber through the Teflon tube and nozzle. The particles ejected from the nozzle impacted with the substrate and were deposited on the substrate surface. The nozzles employed in this experiment had a rectangular orifice of $10.0 \times 0.3 \mathrm{~mm}^{2}$. The substrates were glass plates with a thickness of $1.3 \mathrm{~mm}$ and a surface roughness of approximately $0.02 \mu \mathrm{m}(\mathrm{Ra})$. The thickness and surface roughness of glass plates were measured with a micrometer caliper and a surface profiler, respectively. The distance between the nozzle and the plate was adjusted to be 5 $\mathrm{mm}$. $\mathrm{TiO}_{2}$ film with an area of $10.0 \times 20.0 \mathrm{~mm}^{2}$ on the glass plate was formed by the $\mathrm{TiO}_{2}$ aerosol beam irradiation with the incident angle of $10^{\circ}$. Thickness of the $\mathrm{TiO}_{2}$ film was approximately 10 $\mu \mathrm{m}$. After the $\mathrm{TiO}_{2}$ film was formed, the $\mathrm{TiO}_{2}$ film was irradiated with the HAp aerosol beam for creating the HAp film.

The incidence angle of the HAp aerosol beam was varied from 10 to $60^{\circ}$ with a period of $10^{\circ}$ by rotating the $\theta$ stage for HAp film formation. The $\mathrm{TiO}_{2}$ film position was controlled with an $\mathrm{XYZ}$ stage connected to a computer. An area of $10.0 \times 20.0 \mathrm{~mm}^{2}$ on the surface of the $\mathrm{TiO}_{2}$ film was scanned by the HAp aerosol beam for 1 minute at room temperature. Neither the $\mathrm{TiO}_{2}$ film nor the HAp particles was heated during HAp aerosol beam irradiation.

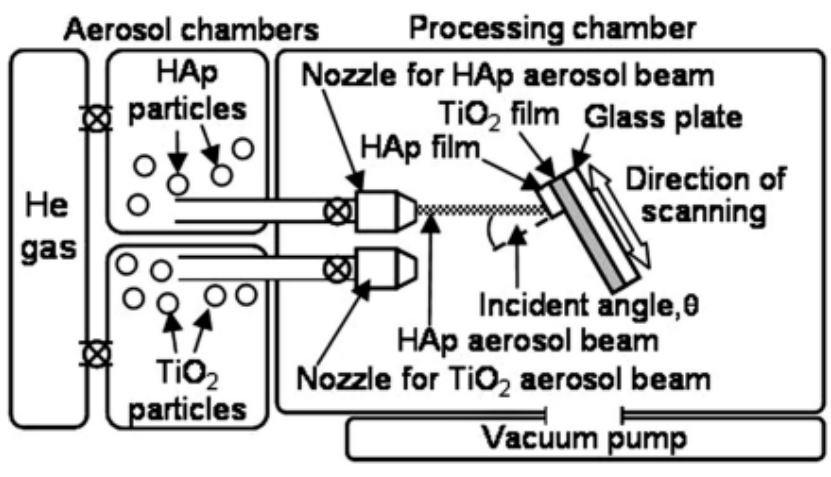

Fig. 1 Schematic diagram of the coating system with two aerosol beams.

Thickness of the HAp film was measured with a surface profiler. Surface morphology of the HAp film was observed with SEM. The $\mathrm{HAp} / \mathrm{TiO}_{2}$ film crystal structure was observed by X-ray diffraction (XRD) analysis.

The decomposition of organic matter on the film was evaluated by temporal variation of the acetaldehyde concentration, which is a conventional method for evaluating the decomposition capacity of $\mathrm{TiO}_{2}$ film. In this study, this method was applied for continuous evaluation of adsorption by the HAp film and decomposition by the $\mathrm{TiO}_{2}$ film. First, the $\mathrm{TiO}_{2}$ or $\mathrm{HAp} / \mathrm{TiO}_{2}$ film was placed in a 1 liter glass container, which was then filled with acetaldehyde adjusted to be an initial concentration of $100 \mathrm{ppm}$. The acetaldehyde concentration was measured at room temperature with gas detection tubes (No.92M, Gastec Corporation, Japan). The acetaldehyde concentration was then measured every 60 minutes for 180 minutes to determine the HAp's adsorption capacity. At 180 minutes (Starting time of UV light irradiation), the surface of the $\mathrm{TiO}_{2}$ or $\mathrm{HAp} / \mathrm{TiO}_{2}$ film in the glass container was irradiated with UV light from a black light source to investigate the decomposition capacity of the $\mathrm{TiO}_{2}$ in the composite film. The film was continuously irradiated for 360 minutes, and the acetaldehyde concentration was measured every 60 minutes.

\section{Results and Discussion}

Thickness of HAp film formed at incidence angles of 10, 20, $30,40,50$ and $60^{\circ}$ are $15,13,9,7,6$ and $3 \mu \mathrm{m}$, respectively. The thickness of the HAp film was decreased from 15 to $3 \mu \mathrm{m}$ as the beam incidence angle was increased from 10 to $60^{\circ}$. The SEM images of the surface of the HAp films produced with the aerosol beam at incidence angles of $10,20,30,40,50$ and $60^{\circ}$ are shown in Figs. 2(a), (b), (c), (d), (e) and (f), respectively. As the images show, the surface morphology was changed as the incidence angle increased. HAp particle shape was observed in Figs. 2(a), (b), (c) and (d). These results suggest that these HAp films at 10, 20, 30 


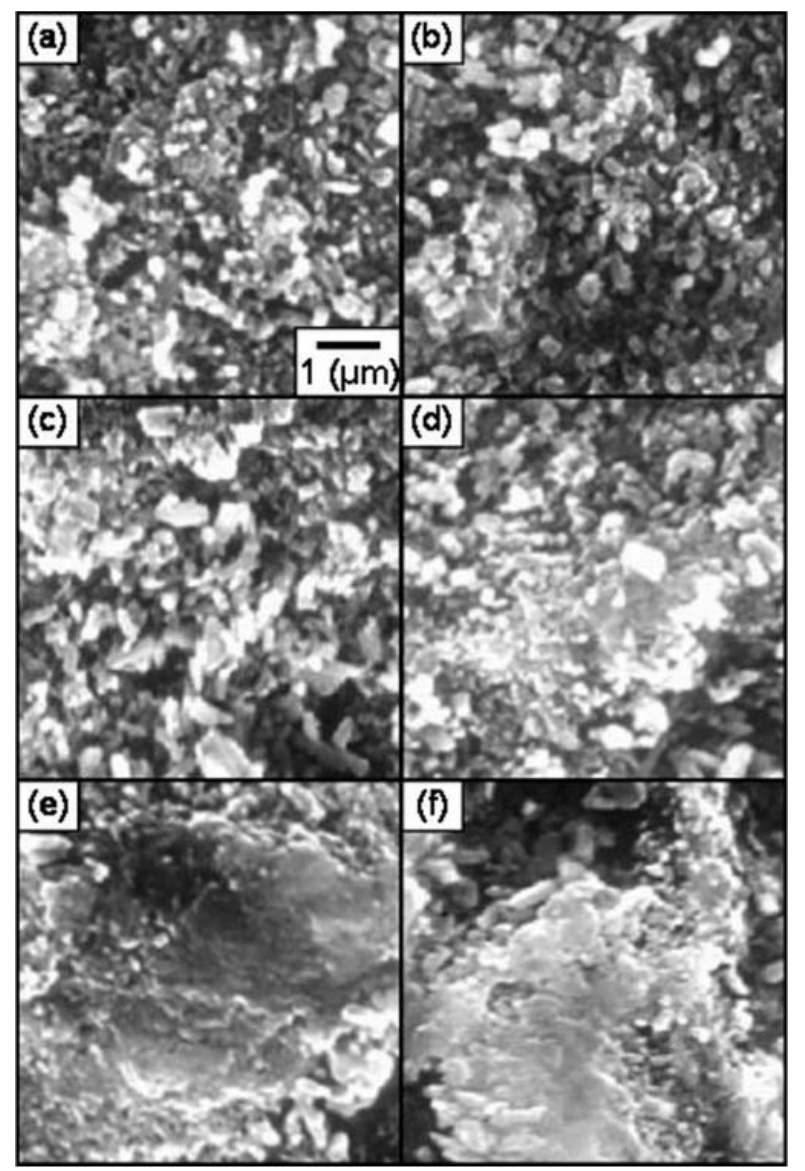

Fig. 2 Surface images of HAp films produced at incidence angles of (a) 10, (b) 20, (c) 30, (d) 40, (e) 50 and (f) $60^{\circ}$.

and $40^{\circ}$ were not dense. In Figs. 2(e) and (f), HAp particle shape was not observed. These results suggest that HAp films at 50 and $60^{\circ}$ were dense. The XRD patterns of $\mathrm{HAp} / \mathrm{TiO}_{2}$ films formed at 10, 20, 30, 40, 50 and $60^{\circ}$ are shown in Figs. 3(a), (b), (c), (d), (e) and (f), respectively. As the patterns show, the crystallinity of HAp was retained throughout the beam irradiation.

Figure 4 shows the acetaldehyde concentration as a function of time. In the 0 to 180 min range, $\mathrm{TiO}_{2}$ and $\mathrm{HAp} / \mathrm{TiO}_{2}$ films were not irradiated with UV light. For $\mathrm{TiO}_{2}$ film, no reduction of the acetaldehyde concentration occurred in 180 minutes. For $\mathrm{HAp} / \mathrm{TiO}_{2}$ films, the acetaldehyde concentration was decreased from 100 to $80 \mathrm{ppm}$ in 180 minutes. These results indicate that $\mathrm{HAp}$ film of the $\mathrm{HAp} / \mathrm{TiO}_{2}$ film adsorbed the acetaldehyde. After UV light irradiation on the films was started, the acetaldehyde concentration was decreased as the irradiation time increased. For $\mathrm{TiO}_{2}$ film, the acetaldehyde concentration was decreased from 100 to approximately $0 \mathrm{ppm}$ for $360 \mathrm{~min}$. For $\mathrm{HAp} / \mathrm{TiO}_{2}$ films at $10,20,30$ and $40^{\circ}$, the concentrations were decreased for $360 \mathrm{~min}$ from 80 to 10, 15, 20 and 25 ppm, respectively. These reductions of the acetaldehyde concentration indicate that the acetaldehyde
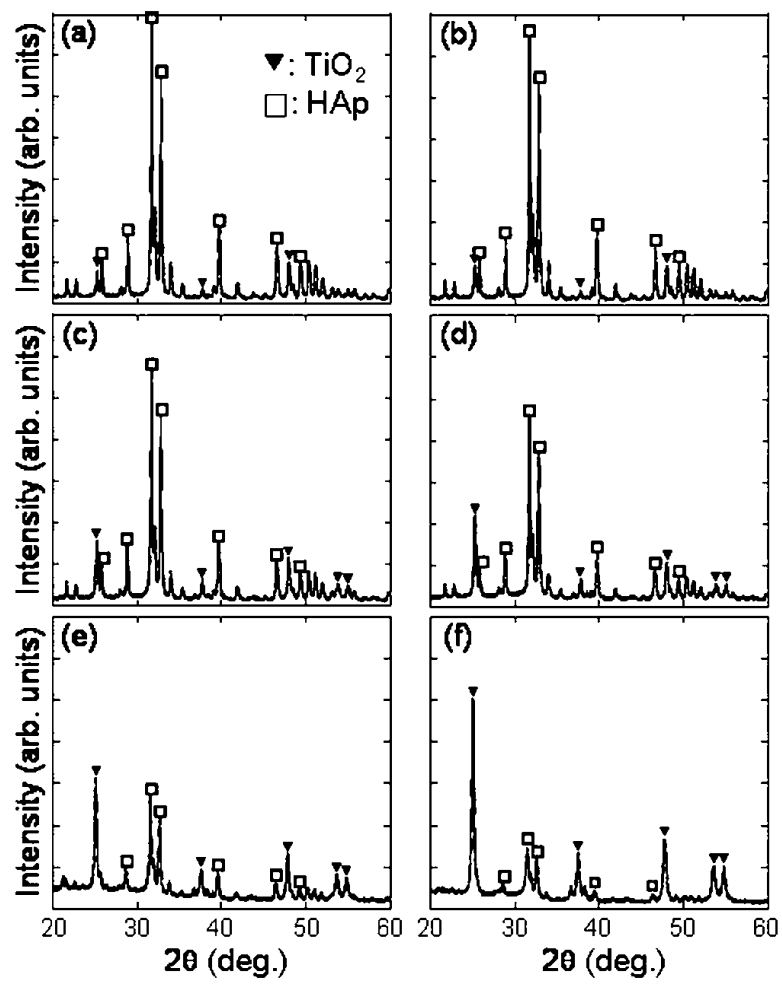

Fig. $3 \mathrm{XRD}$ patterns of $\mathrm{HAp} / \mathrm{TiO}_{2}$ films formed at incidence angles of (a) 10, (b) 20, (c) 30, (d) 40, (e) 50 and (f) $60^{\circ}$.

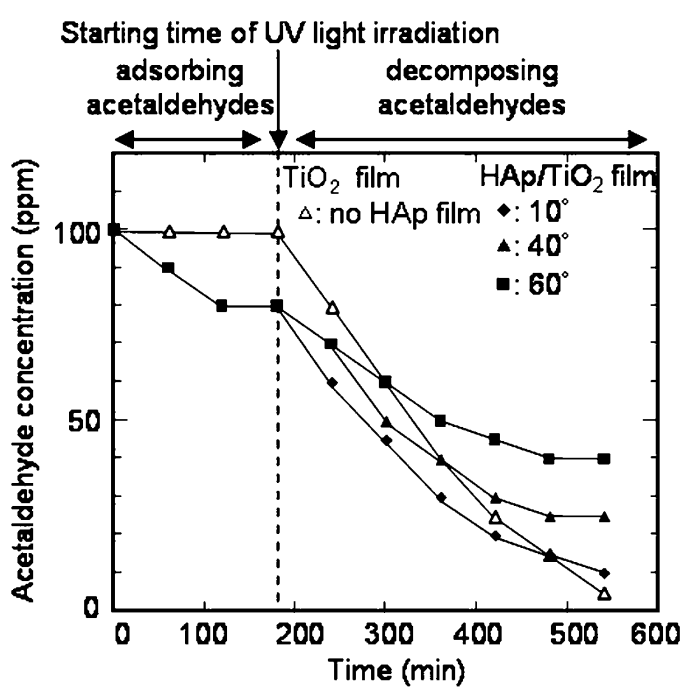

Fig. 4 Acetaldehyde concentrations as a function of time.

contacted the $\mathrm{TiO}_{2}$ films through those HAp films. Reduction rate of the acetaldehyde concentration for $10^{\circ}$ was highest in those for 20,30 and $40^{\circ}$. These results suggests that density of the HAp film at $10^{\circ}$ was lowest in another films' densities. For $\mathrm{HAp} / \mathrm{TiO}_{2}$ films at 50 and $60^{\circ}$, the concentration was varied from 80 to 35 
and $40 \mathrm{ppm}$, respectively. This result suggested that the HAp film of $\mathrm{HAp} / \mathrm{TiO}_{2}$ film at 50 and $60^{\circ}$ had small holes through which the acetaldehyde reached the $\mathrm{TiO}_{2}$ film although it might be dense as shown in Fig. 2(f).

\section{Conclusions}

$\mathrm{HAp} / \mathrm{TiO}_{2}$ films were successfully formed with two kinds of aerosol beam. The XRD pattern of the $\mathrm{HAp} / \mathrm{TiO}_{2}$ film formed at incident HAp aerosol beam angles of 10, 20, 30, 40, 50 and $60^{\circ}$ indicated that anatase phase $\mathrm{TiO}_{2}$ and the HAp structure were retained over the process. HAp film of the $\mathrm{TiO}_{2} / \mathrm{HAp}$ film adsorbed acetaldehyde. The $\mathrm{TiO}_{2} / \mathrm{HAp}$ films decompose acetaldehyde although the $\mathrm{TiO}_{2}$ film was coated with the HAp film. Decomposition rate of the $\mathrm{TiO}_{2} / \mathrm{HAp}$ film produced at $10^{\circ}$ was higher than those produced at 20,30, 40, 50 and $60^{\circ}$.

\section{Reference}

1) A. Fujishima and K. Honda: Bull. Chem. Soc. Jpn., 44 (1971) 1148 1150.

2) A. Fujishima and K. Honda: Nature, 238 (1972) 37 - 38.

3) A. Tiselius, S. Hjertén and Ö. Levin: Arch. Biochem. Biophy., 65 (1956) 132 - 155.

4) T. Fujihara, M. Tsukamoto N. Abe, S. Miyake, T. Ohji and J. Akedo: Trans. Mater. Res. Soc. Jpn., 30 (2005) 1017 - 1020.

5) J. Akedo, M. Ichiki, K. Kikuchi and R. Maeda: Sens. Actuators A, 69 (1998) 106 - 112.

6) M. Tsukamoto, T. Fujihara, N. Abe, S. Miyake, M. Katto, T. Nakayama and J. Akedo: Jpn. J. Appl. Phys., 42 (2003) L120 - L122.

7) T. Fujihara, M. Tsukamoto N. Abe, S. Miyake, T. Ohji and J. Akedo: Vacuum, 73 (2004) 629 - 633.

8) M. Tsukamoto, N. Nakamura, A. Kitajima, J. Morimoto, N. Abe, J. Akedo: Jpn. J. Appl. Phys., 45 (2006) 7840 - 7844. 